\title{
ANALÍTICA E HERMENÊUTICA: DUAS FACES DE UMA MESMA SOLUÇÃO PARA A GARANTLA DA RACIONALIDADE NA APLICAÇÃO DO DIREITO
}

\author{
ANALYTICAL AND HERMENEUTICS: TWO FACES OF A SAME \\ SOLUTION FOR THE GUARANTEE OF RATIONALITY IN THE \\ APPLICATION OF THE LAW \\ Américo Bedê Freire Júnior ${ }^{1}$ \\ Willy Potrich da Silva ${ }^{1}$
}

\begin{abstract}
Recebido em: 26/11/2018 Aceito em: 20/06/2019

bede@jfes.jus.br willypotrich@hotmail.com
\end{abstract}

Resumo: O anseio na busca pela racionalidade das decisões judiciais passa, de modo mais profundo, pela busca de sua legitimidade, especialmente em decisões de grande repercussão e relevância, quando os limites de atuação do Poder Judiciário se confundem com os limites estabelecidos para os Poderes Democráticos. Hermenêutica e Analítica, duas formas distintas de se ver o direito, mostram-se também como duas formas distintas de se enxergar a legitimidade da aplicação do direito, na tentativa de desenhar caminhos que permitam algum tipo de controle sobre a subjetividade inerente a qualquer ato volitivo de decidir. No âmbito da justificação das decisões, surgem as teorias da argumentação jurídica, muito bem condensadas na obra de Manuel Atienza, como mecanismo de exteriorização das razões articuladas no campo da consciência. Em face destas, levanta-se a crítica hermenêutica do direito, trazida na obra de Lênio Streck a partir da hermenêutica filosófica de Gadamer, preocupada com a chancela à indeterminação que se pratica ao considerar suficiente um exercício individual de argumentação em detrimento das verdadeiras razões das decisões. As objeções não anulam ou invalidam qualquer das duas formas de se ver o direito, mas certamente as deve forçar a repensar suas deficiências em uma relação complementar mútua. A resposta, na acepção deste trabalho, está em uma base de argumentação dialética, capaz de permitir a melhor depuração das premissas adotadas e, consequentemente, a aproximação do chamado contexto de descoberta.

Palavras-chave: Argumentação Jurídica. Hermenêutica Filosófica. Jurisdição Constitucional. Legitimidade.

\begin{abstract}
The longing for the rationality of judicial decisions goes deeper in search of its legitimacy, especially in decisions of great repercussion and relevance, when the limits of the Judiciary are confused with the limits established for the Democratic Powers. Hermeneutics and Analytics, two different ways of seeing the law, are also shown as two distinct ways of seeing the legitimacy of law enforcement, in an attempt to design ways that allow some kind of control over the subjectivity inherent in any volitional act to decide. Within the scope of justification of decisions, theories of legal argumentation, very well condensed in the work of Manuel Atienza, appear as a mechanism for externalizing the reasons articulated in the field of consciousness. In the face of these, the hermeneutic critique of law, brought in the work of Lênio Streck from the philosophical hermeneutics of Gadamer, is raised, worried about the endorsement of indetermination that is practiced by considering enough an individual exercise of argumentation to the detriment of the true reasons of the decisions. Objections do not nullify or invalidate either of the two ways of seeing the law, but certainly must force them to rethink their deficiencies in a complementary relationship. The answer, in the sense of this work, is based on a dialectical argument, capable of allowing a better debugging of the premises adopted and, consequently, the approach of the so-called context of discovery.
\end{abstract}

Keywords: Legal Argumentation. Philosophical Hermeneutics. Constitutional Jurisdiction. Legitimacy.

\footnotetext{
${ }^{1}$ Faculdade de Direito de Vitória - FDV - Vitória - Espírito Santo - Brasil
} 


\section{INTRODUÇÃO}

Em entrevista concedida ao portal Consultor Jurídico no ano de 2015, Manuel Atienza, questionado acerca do estado atual de desenvolvimento da teoria do direito no Brasil, respondeu que "correndo o risco de parecer provocador, eu diria que a filosofia do Direito brasileira necessita de menos hermenêutica e mais filosofia analítica" (ATIENZA, 2015).

As declarações de Atienza não ficaram sem resposta. Em artigo publicado no mesmo portal eletrônico, Lênio Luiz Streck, defensor da denominada Crítica Hermenêutica do Direito, chegou a afirmar que seria "ontológicamente impossível pretender mais analítica e menos hermenêutica" (STRECK; OLIVEIRA, 2015).

A contraposição tão marcada entre as duas frases não apenas levanta questões acerca da cooriginalidade ou da precedência de uma determinada filosofia - ou forma de ver o direito - sobre a outra, mas, principalmente, chama atenção para o quanto são raras as produções bibliográficas nacionais voltadas a um diálogo ou mesmo a uma contraposição entre as filosofias, alheia a qualquer potencial de sincretismo, de modo a tornar todas as abordagens sempre isoladas, rígidas, inflexíveis.

Para os fins deste estudo, abre-se mão, desde logo, do fechamento materializado no enunciado apresentado por Streck, que, se tomado em sua literalidade, encerra uma afirmação quase que ininteligível, preso em uma conjuntura de preciosismos filosóficos e carente de melhores explicações, postura que se mostra especialmente delicada por duas razões. Primeiro, diante do indiscutível avanço das teorias da argumentação jurídica que, em suas mais variadas formatações, abandonam progressivamente a ideia mecanicista de subsunção e valorizam a construção discursiva do direito, no que aproximam, cada vez mais, os argumentos jurídicos dos argumentos atinentes à moral, e contribuem para tornar inquietante o terreno teórico acerca da justificação das decisões judiciais. Ainda, em razão da força do precedente no cotidiano da prática jurisdicional - quando uma norma antecedente criada pelo Poder Judiciário em um caso concreto possui, até mesmo, o poder de obstar o processamento de instrumentos recursais, tornando quase automática a aplicação do precedente, numa espécie de operação de simples subsunção - o que torna especialmente relevante uma investigação a respeito de teorias que possam servir de aporte à sua formação.

Toma-se, por isso, a provocação de Atienza como ponto de partida para questionar em que medida as filosofias hermenêutica e analítica se complementam na construção de uma teoria do direito que dê conta de fenômenos característicos do estado do direito atual, como, notadamente, o incremento dos poderes (e da competência) da denominada jurisdição constitucional. Ou, em outros termos, quais são as contribuições epistemológicas fornecidas por ambas acepções do direito em prol da construção de um modelo jurídico que dê conta dos fenômenos que ocupam o cotidiano da prática jurídica nacional.

Apontará, para tanto, breves contornos acerca de ambas as formas de se ver o direito, com especial enfoque para a obra de Manuel Atienza e suas concepções da argumentação, bem como a hermenêutica filosófica defendida por Streck, a partir da obra de Gadamer. Em seguida, a partir de 
suas deficiências, buscará traçar um ponto de aproximação entre as duas "filosofias", de modo a compreender como podem se complementar na delicada questão da operacionalização do direito.

Adotar-se-á como método, para a elaboração do trabalho, a dialética, na medida em que se pretende uma abordagem dialógica entre os autores defensores de uma ou de outra forma de ver o direito. Já no tocante às técnicas investigativas, será realizado o levantamento e o estudo bibliográfico acerca do desenvolvimento das filosofias analítica e hermenêutica no campo do Direito, para, a partir dos dados levantados, responder ao problema proposto para esta pesquisa.

\section{FILOSOFIA ANALÍTICA E A TEORIA DA ARGUMENTAÇÃO DE MANUEL ATIENZA}

Em sua obra acerca da filosofia analítica, Danilo Marcondes aponta-a, numa primeira aproximação, como análise, como decomposição de um todo em partes que serão conceituadas, ou seja, passarão por um processo de definição, consistente, na tradição analítica contemporânea, no apelo à análise linguística. Essas definições, contudo, materializadas em linguagem, não são imutáveis, na medida em que a necessidade de compreender melhor é sempre recorrente (MARCONDES, 2004, p. 8).

A filosofia analítica possui como base seu apoio na linguagem para que seja possível compreender um dado conhecimento, de maneira que não se pode prescindir de uma "questão lógico-linguística" (MARCONDES, 2004, p. 10), que expressa todo conhecimento em linguagem. Assim, de forma objetiva, responde Marcondes que "em termos gerais, a filosofia analítica pode ser caracterizada por ter como ideia básica a concepção de que a filosofia deve realizar-se pela análise da linguagem" (MARCONDES, 2004, p. 12).

Essa análise, contudo, não é unívoca, e pode ser diferenciada, basicamente, em uma formulação binária, que se expressa na passagem do "primeiro Wittgenstein" (apoiado em Frege e Russell) para o "segundo Wittgestein" (seguido por Austin). Naquele, os problemas da análise da linguagem estariam nas deficiências da linguagem natural e, portanto, seriam resolvidas com sua passagem (da linguagem natural) para uma linguagem lógica, mais perfeita e, consequentemente, abstrata, capaz de tornar claros os contornos do pensamento, até então obscurecido pela forma da linguagem ordinária. Já o "segundo Wittgestein" é mais consciente de que não se pode prescindir da realidade ao se analisar a linguagem, ou seja, de que é necessário examinar a linguagem a partir de seu uso, e não mais partir dela para entender a realidade, de modo que se deve clarificar o sentido da experiência por meio da análise do uso da linguagem, suas regras e seu contexto.

A passagem narrada é sintetizada na obra de Marcondes ao tratar da concepção de análise encontrada na Escola de Oxford, para quem:

$\mathrm{Na}$ visão dos filósofos de Oxford a análise não é entendida como decomposição de uma proposição nem como procedimento de tradução de modo a estabelecer a sua forma lógica. Ao valorizar a linguagem comum, ou ordinária, como horizonte de significado de nossa experiência, a filosofia 
de Oxford recusa a reconstrução dessa linguagem em um sentido lógico como solução para os problemas filosóficos ou como um caminho para a elucidação. A análise é vista, assim, como procedimento de elucidação, de esclarecimento, de clarificação, mas do uso da linguagem, das condições que tornam determinados usos possíveis, das regras que o constituem e validam. (MARCONDES, 2004, p. 43).

A filosofia analítica, aplicada ao Direito, redunda na concepção - genericamente considerada - da ciência jurídica como argumentação, ou, dito de outra forma, nas diversas teorias da argumentação jurídica que visam a compreender o direito - sua produção e sua aplicação. Contudo, embora seja mais óbvia a ligação com a segunda visão da análise, as teorias da argumentação jurídica não se limitam a identificar e esclarecer o fenômeno do direito unicamente a partir de seu uso, mas também visam à decomposição das proposições jurídicas - ou fáticas correlatas - em elementos mais simples, que podem ser então sistematizados e estruturados, em um exercício de abstração próprio da lógica.

Essas duas concepções da filosofia analítica se encontram com muita propriedade na obra de Manuel Atienza, que, desde a visão do discurso jurídico como um caso especial do discurso prático, passando pelas aproximações com a lógica dedutiva, até os flertes com a retórica, busca pela formulação de uma teoria própria da argumentação jurídica, capaz de condensar todas as nuances relevantes de um modelo discursivo de formação do direito. Este é o resultado de sua obra "El Derecho como Argumentacion", na qual a argumentação é "analiticamente" subdividida em três dimensões distintas: formal, material e pragmática.

Essas dimensões, longe de excluírem-se, complementam-se, cada qual priorizando um determinado aspecto da argumentação. Enquanto a concepção formal se preocupa com a análise da estrutura - lógica - das argumentações, a concepção formal trata das boas razões empreendidas na atividade argumentativa e a concepção pragmática cuida da função externa dessas razões estruturalmente adequadas (função dialética ou retórica).

O que Atienza, assim como os demais autores da teoria discursiva ou argumentativa do direito, busca fornecer, é um caminho discursivo para a justificação das decisões judiciais, com o objetivo precípuo de tornar evidente - ou explicitar a racionalidade - os processos de aplicação e mesmo de interpretação do direito (que se tornam claros no momento da justificação). Assim, ainda que tais modelos não sejam capazes de oferecer um critério de certeza absoluta na busca pela resposta correta do caso concreto, visam, ao menos, a mostrar um percurso racionalmente adequado à aproximação dessa reposta, seja para o momento de sua elaboração, seja para o momento posterior, de sua análise e crítica, por falhas lógicas, materiais ou performativas.

Portanto, o traço marcante de uma teoria da argumentação jurídica - e não é diferente com o modelo proposto por Atienza - consiste em lançar o foco sobre o momento de justificação da decisão judicial, ou seja, sobre uma espécie de segundo momento, posterior à manifestação psicológica da decisão, como que em uma atividade de defesa da solução previamente escolhida.

De modo geral, assim como se vislumbra na obra de Robert Alexy sobre o tema, a "Teoria da 
Argumentação Jurídica", visam essas teorias da argumentação a aprimorar racionalmente o discurso de justificação da aplicação do direito, cujo aporte teórico não apenas se volta à estrutura de um qualquer tipo de argumentação, mas também ao conteúdo mais geral de uma classe de argumentos e, até mesmo, aos efeitos que esses argumentos terão sobre um determinado grupo de ouvintes. esforço é claro na seguinte passagem da obra de Alexy, que, após citar uma série de obstáculos, conclui:

Disso devemos concluir que, em última análise, a decisão final é baseada em julgamentos de valor e não inter-subjetivamente testados da pessoa que decide, que são o fator decisivo, julgamentos de valor que talvez possam ser explicados em termos sociológicos ou psicológicos, mas que não podem ser justificados? Essa decisão não é justificável na medida em que se refere à legitimidade da tomada judicial de decisão e ao caráter científico da dogmática jurídica em sua preocupação com as questões normativas. Mas isso não seria um argumento para não tomar a decisão, mas um bom motivo para buscar por soluções alternativas. (ALEXY, 201, p. 25).

Estrutura, qualidade e efeitos da argumentação são exatamente os atributos que a obra de Atienza visa a condensar em seu projeto de teoria da argumentação, por meio das já mencionadas concepções da argumentação, cuja análise é essencial para a crítica que se quer fazer à teoria integrada na obra de Manuel Atienza.

Para Atienza a argumentação jurídica é uma atividade complexa, que não se limita exclusivamente à obediência de uma estrutura pré-definida que the confira lógica, mas também releva a importância de seu conteúdo e de seu caráter performativo, como ferramenta de convencimento em um exercício dialético ou retórico. Essa complexidade é materializada nas três concepções da argumentação, que o Autor denomina de formal, material e pragmática (esta, subdividida em retórica e dialética), e que, longe de funcionarem de forma isolada, são complementares entre si, na medida em que, em tradução livre, "o ideal da motivação judicial poder-se-ia expressar, por isso, dizendo que se trata de por as boas razões na forma adequada para que seja possível a persuasão" ${ }^{2}$ (ATIENZA, 2006, p. 97).

A partir das bases lançadas pela lógica dedutiva, o Autor apresenta a concepção formal da argumentação, no sentido de que "la validez formal de los argumentos es (o suele ser) condición necesaria, aunque normalmente no suficiente, de su solidez o corrección material" (ATIENZA, 2006, p. 94). Inobstante compreenda o caráter insuficiente de uma analise meramente formal - lógica - da argumentação jurídica, Atienza compreende que a compreensão de sua estrutura é etapa necessária para que se dê conta de seu conteúdo e de seu efeito pragmático, já que "(...) la corrección formal de los argumentos es, com frecuencia, um instrumento efectivo para lograr persuadir a um auditorio, y,

\footnotetext{
${ }^{2}$ No original: "El ideal de la motivación judicial podría expresarse, por ello, diciendo que se trata de poner las buenas razones en la forma adecuada para que sea posible la persuasión"
} 
desde luego, mostrar la incorrección formal de um argumento es uma poderosa arma dialéctica". (ATIENZA, 2006, p.95).

Não somente o estudo de uma concepção meramente formal se mostra insuficiente, mas, dentro desta - concepção formal - o uso da própria lógica dedutiva se mostra incapaz de dar conta de toda complexidade que surge da tradução da linguagem natural para sua linguagem formal e sistematizada. Por isso, o estudo da estrutura da argumentação jurídica leva em conta elementos de lógicas divergentes e, especialmente, de lógica deôntica, inserindo ao universo lógico de verdade e falsidade - difícil de ser aplicado em relação a normas jurídicas - as noções de validade e os conceitos modais de obrigatoriedade, permissão e proibição, inerentes ao caráter prescritivo das normas.

Como é inerente à lógica, a concepção formal não se preocupa com o estudo do conteúdo das premissas e da conclusão, mas sim com o estudo da inferência, ou seja, com a passagem das primeiras (premissas) para a segunda (conclusão). Mas não é qualquer inferência que interessa à lógica e à concepção forma, uma vez que o estudo não recai sobre conjunturas ou sobre inferências concretas, mas sempre sobre classes de inferências, sobre inferências mais genéricas, abstratas, que possam servir de modelo para inferências concretas que tenham o mesmo padrão.

O saldo são os esquemas lógicos que surgem no ápice da formalização da linguagem natural, expressos em regras lógicas como "Se A e B, portanto B", entre tantas outras (dupla negação, conjunção, separação, expansão, entre outras), sendo o modelo básico traduzido no denominado modus ponens (ATIENZA, 2006. p. 111), capaz de explicar sem maiores problemas a estrutura argumentativa dos casos tidos como fáceis (diante de um fato "F" aplica-se a norma "N"; em um determinado caso, deu-se "F"; portanto, a norma "N" deve ser aplicada).

Esse esquema simplificado, contudo, não dá conta de todos os casos de argumentação com normas, e, de modo geral, apenas consegue explicar a estrutura da argumentação quando esta se desenvolve sobre regras. No que tange, por exemplo, aos princípios, o Autor abandona a lógica deôntica e aborda a formalização materializada na obra de Robert Alexy, especialmente em sua lei da ponderação, que encontra expressão da denominada fórmula do peso (ATIENZA, 2006, p. 172).

A lei da ponderação funciona como uma espécie de premissa geral que deve ser adotada sempre que se tem um conflito entre princípios, e pode ser traduzida na seguinte frase, em tradução livre: "quanto maior é o grau de não satisfação ou de afetação de um dos princípios, tanto maior deve ser a importância da satisfação do outro"3 (ATIENZA, 2006, p. 172). Essa lei se concretiza nas três variáveis da fórmula do peso, que são (a) o grau de afetação de cada princípio no caso concreto, (b) o peso abstrato de cada princípio e (c) a confiabilidade das premissas fáticas adotadas para se aferir a primeira variável. O resultado é o coeficiente dos produtos dessas variáveis, que dirá, em termos matemáticos, qual princípio deve prevalecer no caso concreto.

\footnotetext{
${ }^{3}$ No original, em espanhol: “Cuanto mayor es el grado de la no satisfacción o de afetación de uno de los princípios, tanto mayor debe ser la importância de la satisfacción del outro"
} 
Ainda que não haja espaço para um maior desenvolvimento do tema, o esquema geral que acima se traçou não pode conduzir à percepção de que uma concepção meramente formal da argumentação jurídica poderia encerrar todo o interesse da atividade argumentativa. Para Atienza, não somente a estrutura da argumentação (sua validade), mas também a força dos argumentos, sua relevância, ou mesmo sua aptidão para dar suporte a uma tese (boas razões), devem ser compreendidas na atividade argumentativa.

$\mathrm{Na}$ concepção material, embora menor, preserva-se um certo grau de generalidade. Ainda que a aproximação das contingências se faça necessária para se cuidar do conteúdo argumentativo, o que afasta a possibilidade de se trabalhar apenas com esquemas abstratos (como é na concepção formal), a concepção material também não desce a minúcias para permitir um ajuste teórico à luz de cada caso concreto. Nesta concepção o que se faz é um estudo de tipos de argumentos (e não de argumentos concretos ou tipos de estruturas de argumentos), momento em que se lança luz sobre as premissas utilizadas na concepção formal da argumentação (ATIENZA, 2006, p. 182). Mas, afinal, o que faz algo ser considerado uma boa razão para explicar ou justificar algo, com relativa independência da forma e independente de ser ou não convincente? (ATIENZA, 2006, p. 183).

A boa razão deve ser aquela considerada apropriada para dar conta do resultado da argumentação. Não basta lançar argumentos que soem como prolixos ou "inteligentes" se estes argumentos não derem respaldo à conclusão que se lança na decisão judicial. Mais do que dar conta do resultado, os argumentos lançados devem apresentar uma espécie de compromisso, ou seja, não devem ser inconsequentes, mas devem refletir verdadeiros motivos para se crer em algo ou razões para se atuar em determinada direção. As razões são fatos, que formam o conteúdo dos enunciados (normativos, empíricos etc.), e fazem com que sejam corretos ou verdadeiros.

Em um paradigma no qual a legitimidade das decisões - judiciais e políticas - não se sustenta mais pelos argumentos de autoridade, mostra-se essencial o estudo de uma concepção material da justificação argumentativa. Contudo, esse estudo não seria possível somente a partir dos conceitos de boas razões já alinhavados, mostrando-se essencial que se estabeleça regras de reconhecimento para as razões adequadas:

Assim entendido, pode-se dizer que o conceito de regra de reconhecimento tem um caráter necessário: traça os limites entre a argumentação que é jurídica e a que não é; se não existisse esse criterio, esse limite, não haveria nenhuma diferença entre a argumentação jurídica e a argumentação prática de tipo geral. (ATIENZA, 2006, p. 228). ${ }^{4}$

\footnotetext{
${ }^{4}$ No original: "Así entendido, el concepto de regla de reconocimiento pude decirse que tiene um carácter necesario: traza los limites entre la argumentación que es jurídica y la que no lo es; si no existiera esse criterio, esse limite, no habría ninguna diferencia entre la argumentación jurídica y la argumentación práctica de tipo general."
} 
Essa regra de reconhecimento, no entanto, ao contrário do que se desejaria, não á clara e inequívoca - assim como não parece ser, em geral, a concepção material - tendo por base, resumidamente, a conformação dos argumentos aos princípios de justiça firmado nas constituições dos Estados, em nítida aproximação do direito com a moral, característica do denominado neoconstitucionalismo.

A terceira e última concepção da argumentação na obra de Atienza é a concepção pragmática, que se desdobra em dialética e retórica, e que se revela como a socialização da argumentação, a visão sobre seu papel externo, social, efetivo. Mais uma vez a atenção está nas premissas. Estas, contudo, não exercem o mesmo papel que na concepção material, mas são pontos de partida aceitos ou partilhados, que servirão ao desenvolvimento de um exercício retórico ou dialético.

Na retórica, o exercício argumentativo é unilateral, na medida em que se dirige a um auditório que se coloca exclusivamente na condição de ouvinte, sem participar da atividade argumentativa. Nesta concepção, o caráter externo da argumentação é extremamente limitado e a socialização se resume à transmissão da decisão, com o nítido propósito performativo, voltado a persuadir o público. $\mathrm{Na}$ dialética, por outro lado, tem-se um exercício duplamente ativo, de dois atores da argumentação que participam ativamente do jogo linguístico, na forma de razões e de "contrarrazões", as quais se dirigem uma contra a outra, forçando seu constante aprimoramento (ATIENZA, 2006, p. 260).

Essa preocupação de Atienza com a socialização da argumentação aparece como uma expressão da prevalência da dimensão pragmática da linguagem (performativa), em detrimento da sintaxe e da semântica, pressupondo a linguagem como uma prática, uma atividade, e não somente como um código descritivo (ATIENZA, 2006, p. 247).

Enfim, a concepção pragmática se preocupa com o modo de argumentar, e, por isso, atua em plena sintonia com a concepção formal da argumentação, na medida em que, "a correção formal dos argumentos é, com frequência, um instrumento efetivo para lograr persuadir um auditório e, desde logo, mostrar a incorreção formal de um argumento é uma poderosa arma dialética"5 (ATIENZA, 2006, p. 94).

Essas considerações serão retomadas na última parte deste trabalho, mas, por ora, são suficientes para que se avance no tema.

\footnotetext{
${ }^{5}$ No original: "La corrección formal de los argumentos es, com frecuencia, um instrumento efectivo para lograr persuadir a um auditorio, y, desde luego, mostrar la incorrección formal de um argumento es uma poderosa arma dialéctica"
} 


\section{A CONTRAPOSIÇÃO HERMENÊUTICA}

A concentração de esforços na justificação das decisões judiciais por parte das teorias analíticas, discursivas ou argumentativas é, sem dúvidas, um ponto de forte crítica por parte dos defensores da filosofia hermenêutica, naturalmente preocupada com o momento de descoberta da decisão, com vistas a evitar que seja uma simples opção arbitrária, que se convalida por qualquer processo posterior de justificação.

Ao se tratar da filosofia hermenêutica, deve-se ter o cuidado de não se confundir, ou melhor, de não limitar seu sentido unicamente a uma ideia de interpretação, ou, no caso do direito, como uma simples disciplina assessória na interpretação dos textos jurídicos, como fez, em sua obra "Hermenêutica e Aplicação do Direito", Carlos Maximiliano (2009).

Muito antes disso, com Schleiermacher e sua "Hermenêutica: Arte e Técnica da Interpretação", a hermenêutica ganhava ares de filosofia, de método único destinado a todas as áreas do conhecimento, possuindo como determinantes específicas:

[...] a inseparabilidade entre sujeito e objeto, uma vez que a compreensão hermenêutica se dá pela inserção daquele que compreende no horizonte da história e da linguagem, os quais são aquilo mesmo que deve ser compreendido; o condicionamento de toda expressão do humano a um determinado horizonte linguístico, o que inclui também o resultado da compreensão, portanto, a própria ciência; a circularidade entre o todo e o particular, ou a mútua dependência constitutiva entre a parte e a totalidade, que impossibilita a compreensão por mera indução; e, por fim, a referência a um ponto de vista, ou pré-compreensão, a partir do qual se institui todo conhecimento, que estabelece a prioridade da pergunta sobre a resposta e problematiza a noção de dado empírico puro. (SCHLEIERMACHER, 1999, p. 8).

Em Gadamer, a hermenêutica ganha contornos substancialmente distintos. A partir da filosofia de Heidderger, Gadamer identificará sua hermenêutica filosófica não como um tipo de método qualquer, mas como um existencial, algo inerente à condição de ser humano inserido no mundo, que ocorre naturalmente em todos os nichos da vida cotidiana ou científica. A hermenêutica, assim, estaria ligada ao momento universal da compreensão, que se dá na relação do homem com os outros entes não humanos que o circulam no mundo (CUNHA, 2014, p. 152-153).

Essa compreensão, contudo, não ocorre de forma impessoal, mas somente se torna possível em razão, justamente, das pré-compreensões. Em outras palavras, ao nos lançar ao mundo das experiências, a hermenêutica somente nos permite compreender a partir de uma estrutura de sentidos prévia (NUNES JUNIOR, 2003).

Ao relevar os principais traços da hermenêutica filosófica de Gadamer, Lênio Streck destaca "a reabilitação da autoridade da tradição; a valorização dos pré-conceitos para o acontecimento da 
compreensão; e a distância temporal como fator determinante para o desenvolvimento de horizontes interpretativos mais adequados" (STRECK, 2015).

Por isso, trazido para o âmbito do direito e de sua aplicação, o "discurso" hermenêutico não volta suas atenções à justificação das decisões judiciais, mas a um momento prévio, anterior e necessário, consistente na compreensão que ocorre simultaneamente ao momento de aplicação do direito:

Como olhamos o antes na determinação do agora, a decisão correta/adequada será bem (constitucionalmente) fundamentada e não apenas argumentativamente adequada, pois, caso contrário, corre-se o risco de o jurista contentar-se com uma retórica acerca do direito. Ou seja, corre-se o risco de deixar que o juiz faça a sua escolha, para, depois, contentarmo-nos com uma boa argumentação a favor de sua escolha. Ocorre que, antes deste segundo momento, a escolha pode ter sido incorreta. É por isso que a CHD preocupa-se com a decisão, que não pode ser um ato de escolha. Aqui me permito colocar o "dilema da ponte", que ajuda a explicar o problema do "decidir primeiro e fundamentar depois". Como posso atravessar o abismo gnosiológico do conhecimento, chegar do outro lado e depois retornar para construir a ponte pela qual eu já passei? Eis a questão. A ponte é condição de possibilidade. Ela é o fundamento. Por isso, para a hermenêutica (CHD), o juiz não decide para, só depois, buscar a fundamentação. Ele só decide porque tem a fundamentação que lhe é condição prévia. Caso contrário, caímos em um teleologismo. Decidir não pode ser um ato de vontade. (STRECK, 2016)

O fundamento estrutural da compreensão a partir da filosofia hermenêutica localiza-se no denominado círculo hermenêutico, elemento figurativo que ilustra o movimento da compreensão em sua formação sempre dependente das pré-compreensões do sujeito que se debruça sobre o texto. Este, a partir de sua carga de experiências, projeta imediatamente o sentido do todo a partir do primeiro sentido que se depreende do texto.

Contudo, essa compreensão imediata não pode ser congelada no tempo. Pelo contrário, deve sempre estar sujeita a constante revisão, constante autocrítica, especialmente a partir da alteridade que se deve reconhecer no texto. Aqui se aperfeiçoa a ideia do círculo hermenêutico quase que em um movimento espiral, que se fortalece pelo caráter invariavelmente intersubjetivo que se reconhece ao momento da compreensão. Nas palavras de Gadamer:

Quando se ouve alguém ou quando se empreende uma leitura, não é necessário que se esqueçam todas as opiniões prévias sobre seu conteúdo e todas as opiniões próprias. O que se exige é simplesmente a abertura à opinião do outro ou à do texto (...) Uma consciência formada 
hermeneuticamente tem que se mostrar receptiva, desde o princípio, para a alteridade do texto. Mas essa receptividade não pressupõe nem neutralidade com relação à coisa nem tampouco auto-anulamento, mas inclui a apropriação das próprias opiniões prévias e preconceitos, apropriação que se destaca destes. O que importa é dar-se conta das próprias antecipações, para que o próprio texto possa apresentar-se em sua alteridade e obtenha assim a possibilidade de confrontar sua verdade com as próprias opiniões prévias (GADAMER, 1997, p. 404-405).

Há, portanto, um equilíbrio de forças: o intérprete não se deixa inundar pela alteridade do texto, mas, também, não sufoca o sentido do texto em razão de suas compreensões. Estas, por sua vez, não se limitam a pré-conceitos do sujeito, mas são "a realidade histórica de seu ser", expressão do resgate da autoridade da tradição, que determina, afinal, a pré-estrutura da compreensão. Como escrevem Moreira e Cabral, a partir da obra de Palmer, "o passado não é como um amontoado de factos que se possam tornar objecto de consciência; é antes um fluxo em que nos movemos e participamos, em todo o acto de compreensão" (MOREIRA; CABRAL, 2008, p. 144).

$O$ ato de interpretar se dá sempre a partir de uma visão de mundo, de uma espécie de lente da qual se veste o intérprete para compreender um objeto. Não só o horizonte de interpretação do intérprete está condicionado pela autoridade da tradição mas também o próprio texto interpretado possui seu próprio horizonte, os quais devem entrar em contato e se fundir, como consectário do reconhecimento da alteridade do que se propõe a compreender.

Essa fusão de horizontes, para Gadamer, ocorre através do diálogo entre o intérprete e o texto, por meio de perguntas - feitas pelo sujeito - e respostas - fornecidas pelo texto - em razão das quais o intérprete consegue penetrar no que está escrito e compreender a perspectiva histórica do que se lê, ou seja, o horizonte histórico do texto (MOREIRA; CABRAL, 2008, p. 148), fundamental à fusão de horizontes reconhecida como fundamental por Gadamer (STRECK, 2007, p. 211).

Por isso, da filosofia hermenêutica, os pré-conceitos e a distância temporal que separa o intérprete do texto não são vistas como obstáculos à compreensão, mas como ferramentas que devem ser utilizadas pelo intérprete em sua tarefa de compreender. Como afirma Streck, "esses elementos geram um quadro que permite pensar o problema hermenêutico fora do polo da subjetividade, abrindo caminho para o (...) "paradigma da intersubjetividade"” (STRECK, 2015). E mais:

Os sentidos, portanto, não dependem da consciência de quem compreende ou interpreta (no caso do direito, o exemplo privilegiado é o do julgador), mas, sim, de sua inserção em um mundo repleto de significados compartilhados intersubjetivamente.

A partir da ótica da intersubjetividade a crítica hermenêutica às teorias discursivas do direito ganha notória expressão, especialmente quando se concebe que a atividade de decidir pode ser um 
amontoado solitário de razões fabricadas por um intérprete que, antes de qualquer caminho analítico, já tem formada sua conviç̧ão. Este, aliás, parece ser um risco aceito sem maiores problemas pelas teorias da argumentação, e pelo próprio Manuel Atienza (2003, p. 22):

Pode-se também estender a distinção ao campo da argumentação em geral e ao da argumentação jurídica em particular (cf. Wasserstrom, 1961, e Golding, 1984, págs. 22-3). Assim, uma coisa é o procedimento mediante o qual se estabelece uma determinada premissa ou conclusão, e outra coisa é o procedimento que consiste em justificar essa premissa ou conclusão. Se consideramos o argumento que conclui afirmando ser "necessário alimentar à força os detentos do GRAPO", a distinção pode ser traçada entre as causas psicológicas, o contexto social, as circunstâncias ideológicas etc. que levaram um determinado juiz a emitir essa resolução, e as razões dadas pelo órgão em questão para mostrar que a sua decisão é correta ou aceitável (que está justificada). Dizer que o juiz tomou essa decisão devido às suas fortes crenças religiosas significa enunciar uma razão explicativa', dizer que a decisão do juiz se baseou numa determinada interpretação do artigo 15 da Constituição significa enunciar uma razão justificadora. De modo geral os órgãos jurisdicionais ou administrativos não precisam explicar as suas decisões; o que devem fazer é justificá-las.

Aliás, cuida-se de visão inerente aos teóricos da argumentação jurídica, como se verifica a partir das palavras de McCormick:

Logo, a noção essencial é a de dar (o que se entende por, e é apresentado como) boas razões justificatórias em defesa de reivindicações ou decisões. O processo que vale estudar é o processo de argumentação como processo de justificação. (...) De modo semelhante, o que leva um juiz a considerar vitoriosa uma parte em vez da outra é uma questão totalmente diferente do fato de saber se a reflexão nos revela haver boas razões justificatórias mais favoráveis a uma parte que à outra. (MCCORMICK, 2006, p. 19-20).

\section{A MIOPIA JUSTIFICADORA, A ILUSÃO DA DESCOBERTA E A CONCEPÇÃO PRAGMÁTICA COMO PONTO DE CONTATO}

Hermenêutica e analítica, ambas as formas de se ver o direito são dotadas de suas próprias vicissitudes. O ponto crítico da hermenêutica para o resultado da compreensão se mostra a consideração, dentro do círculo hermenêutico, dos objetivos prévios do sujeito que se propõe a 
interpretar. Ainda que se trabalhe sempre dentro do cenário ideal da boa-fé do agente, sentimentos negativos, desafetos, experiências ruins ou outras formas de pré-compreensões que influenciam no horizonte do agente podem gerar, mesmo de forma inconsciente, um resultado ilegítimo que ignora a alteridade do texto interpretado e faz calar a fusão de horizontes que deveria ser a equação do resultado interpretativo.

A descoberta, nesse cenário, aparece como uma construção de correção ilusória, na qual o intérprete não consegue retratar o resultado da fusão de horizontes legítima que deveria surgir do exercício interpretativo, deixando que o resultado seja o encobrimento da alteridade do texto interpretado em razão de toda sorte de elementos subjetivos que compõe a denominada précompreensão.

A solução para este problema, por tudo que até aqui se expôs, poderia parecer simplória. Bastaria a adoção de uma teoria da argumentação, capaz de explicitar as razões verdadeiramente utilizadas pelo julgador - ou por um outro intérprete do direito - em sua tomada de decisão. Ainda que esta seja parte do que se entende como solução, ela, adotada de forma pura e simples, apenas deslocaria o horizonte de aparecimento do mesmo problema, no que redunda, aliás, o ponto fraco das teorias da argumentação.

Nestas, a partir da completa aversão ao momento da descoberta, o risco é que o encobrimento do mesmo tipo de subjetivismo seja feito a partir de pomposas razões utilizadas com graus mais variados de eloquências, num exercício artificial em que a argumentação não passa de uma explicação para uma decisão anterior, sem compromisso necessário com cada uma das concepções argumentativas expostas por Atienza, e acima explicitadas.

O risco se transforma em um verdadeiro contrassenso quando se observa que a justificativa de Atienza para uma concepção da argumentação jurídica voltada exclusivamente à estrutura dessa atividade (concepção formal) é justamente identificar premissas ocultas que possam estar presentes no raciocínio jurídico, e que não venham à tona quando se considera bastante somente o contexto de descoberta da decisão. Ora, nenhum terreno mais fértil para a ocultação de premissas do que aquele criado pela pura e simples justificação procedimental das decisões judiciais.

O par de problemas apresentados aponta desde logo para a complementariedade das visões que até aqui se apresentam como antagônicas. O ponto fraco da hermenêutica filosófica tem seu preenchimento nas teorias da argumentação jurídica, e a farsa que as teorias discursivas podem encobrir tem seu antídoto no retorno ao contexto de descoberta, inerente à hermenêutica. Daí ser correto que não se possa prescindir de qualquer desses momentos. Descoberta e justificação, como duas faces de uma mesma solução voltada à busca de critérios racionais para a legitimação das decisões judiciais, parecem ser momentos que somente se dividem para fins de discussões filosóficas, mas que, na prática, são irmãs. Esse, ainda que com os olhos aparentemente voltados para algum tipo de precedência hermenêutica, parece ter sido o resultado do trabalho de Ricarlos Almagro Vitoriano Cunha (2014, p. 211), ao afirmar:

De nada adiantaria postular ao discurso jurídico a função realinhadora e corretiva do pensamento, se nele ingressamos na contramão da verdade. 
Há traços éticos que nos obrigam a colocar-nos na "situação discursiva" com uma certa disposição afetiva voltada a permitir a liberdade do outro. Se no plano da hermenêutica (isolando apenas para fins analíticos) o que é determinante é a supressão de decisionismos assujeitadores e objetivismos que suprimem o chão da vida; no âmbito da argumentação, o que importa é que nela ingressemos de forma ética. De um lado contrapomos a questão fulcral da decisão não arbitrária e, de outro, a convivência em liberdade.

Caso se queira que a legitimação para a formação dos precedentes, especialmente no âmbito da jurisdição constitucional, esteja localizada (no bojo de um Estado democrático de Direito) em uma teoria de discurso racional, esta não pode conceber o magistrado como um ente isolado do mundo, criador solitário de todas as verdades. Por isso, mesmo uma legitimação baseada no discurso parece exigir maiores reflexões para que não se transforme, a pretexto de justificação, em método aplicável após o resultado, como um instrumento justificador de arbitrariedades, desvinculado do momento de escolha da decisão e preocupado, unicamente, com a forma se sua exteriorização.

Se já se tem como certo que não se pode prescindir de um momento de justificação para legitimar o exercício interpretativo levado a efeito no contexto da descoberta, é necessário agora evidenciar como esse contexto de justificação pode cumprir seu papel sem abandonar a preocupação com as verdadeiras razões da decisão, ou com as premissas que possam se ocultar por trás de um jogo bem elaborado de argumentação.

A solução está em estabelecer um diálogo franco entre as teorias da argumentação jurídica, que aqui se tomam na síntese formulada pelo professor Manuel Atienza, e a hermenêutica Gadameriana ou a crítica hermenêutica do Direito, como denominada por Lênio Luiz Streck, diálogo este que se manifesta, dentro do projeto de teoria da argumentação jurídica trazido na obra de Atienza, na denominada concepção pragmática da argumentação jurídica.

O ideal de racionalidade na justificação das decisões judiciais cai por terra quando se assume que o exercício de justificação se desenvolve livremente com base em razões diversas daquelas que levaram à tomada da decisão. Não há qualquer utilidade em um cuidadoso trabalho de justificação, preocupado com a estrutura formal dos argumentos e com seu conteúdo, se a atividade argumentativa não se desenvolve com base nas razões que verdadeiramente levaram à tomada da decisão. A argumentação não pode assumir um jogo de escolha e exposição dos melhores argumentos, mas deve funcionar verdadeiramente como justificação, ainda que se possa questionar sobre a capacidade desse tipo de abordagem realmente captar todos os fatores que levaram à tomada da decisão.

Não se tem a inocência de acreditar que uma teoria da argumentação possa ser infalível no momento de desvendar as razões levadas em conta, mas, ao menos, deve ser capaz de fornecer um caminho de descoberta da descoberta, uma forma de localizar onde residem as razões fundamentais para a tomada da decisão, papel que confere especial relevância à concepção pragmática da argumentação, em sua função de socialização da decisão. 
Em termos mais simples, se as teorias da argumentação jurídica não são capazes de trazer os elementos necessários a uma reposta definitiva, ao menos parecem ser capazes, no modelo parcial aqui exposto com base na obra de Atienza, de evitar que as razões subjacentes sejam simplesmente ignoradas e que a decisão seja sempre uma via de mão única.

Como já se adiantou, o caminho argumentativo para uma aproximação da descoberta está na concepção pragmática da argumentação, mais especificamente em sua dimensão dialética, sobretudo quando o próprio Atienza, a partir da dimensão retórica da pragmática argumentativa, destaca que possui como problema fundamental "o de sua legitimidade, pois se a retórica é meramente uma técnica, um procedimento para persuadir, essa técnica pode ser usada para persuadir acerca do que é falso ou injusto, ou seja, pode ser usada para lograr fins ilegítimos" 6 (ATIENZA, 2006, 273). E mais:

$\mathrm{Na}$ argumentação dialética (o que está também ligado com o anterior) existe a oportunidade de examinar os prós e conrtras de uma situação, de uma tese, enquanto a argumentação retórica tem um caráter mais unitário: o discurso dialético avança, vale dizer, em forma de espiral (ou como uma linha quebrada), enquanto que o retórico é mais unidirecional. ${ }^{7}$ (2006, p. 260).

O problema de legitimidade da socialização retórica destaca de forma enfática a importância de se valorizar a dialética no exercício argumentativo, posto que esta "está mais vinculada à filosofia, à descoberta da verdade8" (ATIENZA, 2006, p. 261). O movimento espiral da argumentação dialética, destacado por Atienza, mostra-se como a materialização da alteridade que se tem como inerente ao círculo hermenêutico, dentro do campo da justificação. A intersubjetividade alcançada pela socialização que se baseia em um exercício dialético garante premissas mais apuradas, expostas a testes públicos de idoneidade e mesmo de legitimidade.

A valorização do exercício argumentativo dialético também agrega ao momento de justificação da decisão judicial valores afetos à participação e, naturalmente, à ideia de democracia, ainda que limitada pelos moldes inerentes a um processo judicial, no qual "há regras de procedimento que regulamentam o debate e o terceiro (o juiz ou o jurado) que resolve que parte é a vencedora" 9 (2006, p. 265).

A importância de um exercício dialético subjacente ao processo argumentativo, como forma de depuração de premissas, e de aproximação do que se tem por contexto de descoberta, parece ter

\footnotetext{
${ }^{6}$ No original: "El de su legitimidad: pues si la retórica es meramente una técnica, un procedimiento para persuadir, esa técnica puede usarse para persuadir de lo falso o de lo injusto, esto es, puede usarse para lograr fines ilegítimos."

${ }^{7}$ No original, em espanhol: "En la argumentación dialéctica (lo que está también ligado con lo anterior) existe la oportunidad de examinar los pros y contra de una situación, de una tesis, mientras que la argumentación retórica tiene un carácter más unitario: el discurso dialéctico avanza, cabría decir, en forma de espiral (o como una línea quebrada), mientras que el retórico es más unidireccional."

${ }^{8}$ No original: "Está más vinculada a la filosofía, al descubrimiento de la verdad."

${ }^{9}$ No original: "hay reglas de procedimiento que reglamentan el debate y un tercero (el juez o el jurado) que resuelve qué parte es la vencedora".
} 
correspondência em estudos nos quais se compreende que o desenvolvimento da razão humana não se deu na perspectiva do aumento de conhecimento, mas sim do aumento do sucesso em debates. $O$ resultado é simplório: as chances de sucesso de uma argumentação que leve em conta outros atores é muito mais significante do que argumentações isoladas, chafurdadas em convicções pessoais:

Por fim, a formulação teórica que recentemente mais tem ganhado atenção é a "Teoria Argumentativa do Raciocínio", formulada por Hugo Mercier e Dan Sperber. Os autores propõem que, em vez de pensarmos que a argumentação advém do raciocínio, devemos encarar a principal função do raciocínio como argumentativa, isto é, os seres humanos raciocinam sobre problemas por meio da necessidade da produção de justificativas. Encontrando bons argumentos para defender seu ponto de vista, as pessoas não se dão ao trabalho de se engajar em exaustivos raciocínios deliberativos, porém, caso precisem justificar seu ponto de vista diante de uma audiência, isso as obriga a refletir mais e a produzir melhores argumentos. Em caso de discordâncias de opinião, as pessoas tendem a ser muito vigilantes em relação a argumentos contrários aos seus, buscando contestá-los - e, caso não encontrem argumentos suficientes em defesa de sua posição, e tenham motivos para ter credibilidade no interlocutor, podem mudar de ideia. Assim, discussões de grupo podem ser efetivas quando os seus membros estiverem efetivamente engajados em encontrar a resposta correta para um problema.

(...)

A Teoria Argumentativa do Raciocínio integra em um só marco teórico os achados da literatura psicológica recente e ajuda a explicar diversos vieses no raciocínio, como a dissonância cognitiva, o viés de confirmação e o raciocínio motivado. $47 \mathrm{E}$, do ponto de vista da presente discussão, sugere que a existência de contextos de justificação mais exigentes pode levar a processos de descoberta mais rigorosos e menos enviesados. (HORTA; COSTA, 2017).

A vantagem de um modelo que force o aperfeiçoamento das justificativas está em afastar razões que somente sejam boas para fins estéticos ou retóricos, mas que não guardam relação com o contexto de descoberta da decisão. Estas razões, colocadas em um processo intersubjetivo de argumentação, podem revelar sua inviabilidade frente a determinadas contrarrazões, que não aparecem em um modelo unicamente retórico, de auditório passivo. A consequência invariável é a aproximação do momento da justificação com o momento de descoberta tão caro à filosofia hermenêutica, senão para garantir que venham sempre à tona as verdadeiras razões levadas em conta por quem decide, mas, ao menos, para dificultar consideravelmente a dissimulação dos argumentos em desconformidade com as subjacentes razões. 
Inclusive, a ideia de aproximação entre ambas as formas de se ver o direito é exatamente o que defende Manuel Atienza, ainda que em contornos distintos dos esboçados neste trabalho, em resposta veiculada no mesmo portal jurídico em face das críticas de Streck. É o que fica claro quando afirma que "Não creio (ao contrário do que supõem meus interlocutores) que a hermenêutica e a filosofia analítica sejam concepções necessariamente incompatíveis entre si" (ATIENZA, 2015a), e, ainda, que "os juízes e, em geral, os juristas fariam muito bem em tomar elementos dessas concepções para resolver os problemas interpretativos que devem enfrentar em sua prática" (ATIENZA, 2015a). Em seguida, de modo muito mais voltado à contribuição da analítica para com a hermenêutica, do que o contrário, argumenta a partir do objetivismo moral de Dworkin ${ }^{10}$ (como expressão hermenêutica):

E, a propósito disso, eu gostaria de esclarecer duas coisas. A primeira é que o objetivismo moral que eu defendia na entrevista (e pelo qual Oliveira e Streck não parecem ter precisamente simpatia) é de um tipo muito parecido ao que se pode encontrar na obra de Dworkin: não um objetivismo que pressuponha o realismo moral, mas um objetivismo das razões, a ideia de que sobre as questões morais, valorativas, é possível construir um discurso racional dotado de critérios de correção. E a segunda é que a concepção argumentativa do Direito, que eu tratei de construir, parte dessa concepção, digamos, complexa da interpretação: uma concepção que não descuida dos elementos "hermenêuticos", mas que trata de integrá-los com os de caráter técnico-jurídico (esquemas lógicos dos argumentos, natureza e peso dos critérios - cânones - interpretativos, etc.). (ATIENZA, 2015a).

Ao final, enxergando aparentemente na concepção material da argumentação o ponto de contato que aqui se identificou na concepção pragmática, conclui sob o argumento de que "que uma das maiores contribuições a esse componente material da argumentação encontra-se precisamente na obra de Dworkin" (ATIENZA, 2015a).

\section{CONSIDERAÇÕES FINAIS}

Não se deve estabelecer relações de precedência e muito menos ignorar qualquer das duas formas. Analítica e hermenêutica, justificação e descoberta, são momentos complementares e interdependentes. Se por um lado a descoberta não pode prescindir de um momento posterior de justificação, cujo caminho é traçado pelas teorias discursivas do direito, por outro a justificativa não

\footnotetext{
${ }^{10}$ Para Dworkin, o foco na argumentação faz com que se avolumem decisões baseadas em fundamentos não jurídicos, que são apenas revestidos de uma aparência de legalidade, razão pela qual "torna-se fundamental a utilização de parâmetros decisórios que incitem a obrigação dos juízes de solucionar os casos, utilizando-se de argumentos que justi\# quem a solução dada e que demonstrem a sua adequação ao caso, o que, em Dworkin, signi\# ca decidir o direito sob à melhor luz moral." (VERBICATO; OLIVEIRA, 2018).
} 
pode encerrar um artifício alegórico, divorciado das verdadeiras razões que, no momento anterior, levaram à tomada da decisão.

A relevância de se buscar a aproximação e a exposição entre os contextos de descoberta e justificação ganha especial relevo no bojo da denominada jurisdição constitucional, especialmente quando se observa a envergadura de decisões tomadas pelo Supremo Tribunal Federal, que, sob o pretexto de guarda da Constituição, mostram-se como verdadeiras inovações legislativas levadas a efeito por um órgão essencialmente não democrático.

Exposições de longas justificativas em um modelo de exteriorização meramente retórico apenas contribuem para aumentar a sensação, surgida desde a famosa objeção de Carl Schmitt a Hans Kelsen, no sentido de que o Tribunal Constitucional estaria fadado a se transformar em uma instância política dotada de poderes legislativos constitucionais.

Embora o apontamento de exemplos seja delicado - em razão de controvérsias jurídicas legítimas que deles se possa extrair - é certo que há ocasiões nas quais os caminhos percorridos pela jurisdição constitucional causam mais indagações do que justificações, tornando clara a insuficiência dos bons argumentos para fins de legitimação (que vai muito além da simples justificação).

São, por exemplo, os casos das decisões acerca da possibilidade de prisão pena a partir da condenação em segunda instância ${ }^{11}$, a descriminalização do aborto, em pronunciamento de ofício, em sede de habeas corpus, no primeiro trimestre de gestação ${ }^{12}$, bem como o estranho fenômeno da mutação constitucional que estaria se operando sobre o sentido do art. $52, X$ da Constituição Federal13. Em todos estes casos, seja por especulações de cunho político-partidário, seja por especulações de cunho político em uma acepção mais ampla da palavra, as decisões do Supremo Tribunal Federal parecem cada vez menos refletir na sociedade civil a expectativa de legitimidade e de juridicidade que seria de se aguardar de qualquer decisão de uma corte constitucional.

Embora não seja simples estabelecer graus de dificuldade ou simplicidade em matéria de direito, esse tipo de relação entre hermenêutica e analítica se mostra especialmente proveitosa em casos considerados de grande repercussão social, ainda que tal juízo esteja sujeito à discricionariedade do órgão julgador. Decisões que tratem de temas polêmicos e com potencial de grave repercussão, como se dá no controle abstrato de constitucionalidade, em ações coletivas (especialmente aquelas lastreadas em direitos difusos) e em demandas que cuidem, de forma paradigmática, de tema complexo envolvendo o conflito entre direitos fundamentais.

Por isso, imprescindível se mostra, em decisões com tal repercussão (aliás, em toda e qualquer decisão, mas, com o foco em um exercício dialético aberto em uma arena argumentativa, especialmente nestas), que a justificação não ignore o momento da descoberta, e que esta - a

\footnotetext{
${ }^{11}$ Decisão no HC 126.292-SP, de Relatoria do Ministro Teori Zavascky, julgado em 17/02/2016 pelo plenário do Supremo Tribunal Federal. Constou de sua ementa: “A execução provisória de acórdão penal condenatório proferido em grau de apelação, ainda que sujeito a recurso especial ou extraordinário, não compromete o princípio constitucional da presunção de inocência afirmado pelo artigo $5^{\circ}$, inciso LVII da Constituição Federal". ${ }^{12}$ STF, HC 124.306, de relatoria do Ministro Marco Aurélio Mello.

${ }^{13}$ A interpretação teve lugar após a declaração incidental de inconstitucionalidade do art. $2^{\circ}$ da Lei 9.055/1995, no julgamento conjunto de improcedência das ADI`s 3406 e 3470, ambas do Rio de Janeiro e de relatoria da Ministra Rosa Weber.
} 
descoberta - ocorra com o viés mais democrático possível, ainda que dentro de um órgão essencialmente burocrático, como é o Supremo Tribunal Federal, e no mais, todo o Poder Judiciário. Tal função apenas pode ser exercida por algo como a concepção pragmática da argumentação (ou instrumentos argumentativos semelhantes), capaz de fazer surgirem, nas discussões legítimas travadas entre os atores processuais (partes, magistrado, Ministério Público, amici curiae etc.), as premissas reais da decisão, que poderão ter sua fragilidade exposta na arena da contraargumentação.

\section{REFERÊNCIAS}

ALEXY, Robert. Teoria da Argumentação Jurídica. São Paulo: Landy Editora, 2001.

ATIENZA, Manuel. "Discussão sobre neoconstitucionalismo é um acúmulo de equívocos". Entrevistador: André Rufino do Vale. Brasília: 2015. Entrevista concedida à Revista Eletrônica Consultor Jurídico. Disponível em < https://www.conjur.com.br/2015-set-05/entrevista-manuel-atienzaprofessor-universidade-alicante>. Acesso em 10 nov. 2018.

ATIENZA, Manuel. El derecho como argumentación. Barcelona: Ariel, 2006.

ATIENZA, Manuel. Razões do direito: teorias da argumentação jurídica. 3. ed. Tradução de Maria Cristina Guimarães Cupertino. São Paulo: Landy, 2003.

BONAVIDES, Paulo. Jurisdição constitucional e legitimidade (algumas observações sobre o Brasil). Estud. av., São Paulo, v. 18, n. 51, p. 127-150, Ago. 2004 . Disponível em $<$ http://www.scielo.br/scielo.php?script=sci_arttext\&pid=S0103-

40142004000200007\&lng=en\&nrm=iso>. Acesso em 03 Jul. 2018. http://dx.doi.org/10.1590/S010340142004000200007.

BRASIL. Supremo Tribunal Federal. Habeas Corpus 124306/RJ. Relator Ministro Marco Aurélio, Brasília, 29 de novembro de 2016.

BRASIL. Supremo Tribunal Federal. Habeas Corpus 126292/SP. Relator Ministro Teori Zavascky, Brasília, 17 de fevereiro de 2016.

BRASIL. Supremo Tribunal Federal. Ação Direta de Inconstitucionalidade 3406. Relatora Ministra Teori Zavascky, Brasília, 29 de novembro de 2017.

CUNHA, Ricarlos Almagro Vitoriano. Hermenêutica e Argumentação no Direito. Curitiba: CRV, 2014.

HORTA, Ricardo Lins; COSTA, Alexandre de Araújo. Das Teorias da Interpretação à Teoria da Decisão: Por uma Perspectiva Realista Acerca das Influências e Constrangimentos Sobre a Atividade Judicial. Revista Opinião Jurídica, Fortaleza, Fortaleza, ano 15, n. 20, p.271-297, jan./jun. 2017. Disponível em <https://periodicos.unichristus.edu.br/opiniaojuridica/article/download/1387/470>. Acesso em 10 nov. 2018.

MARCONDES, Danilo. Filosofia Analítica. Rio de Janeiro: Jorge Zahar Editor, 2004.

MAXIMILIANO, Carlos. Hermenêutica e Aplicação do Direito. Rio de Janeiro: Editora Forense, 2009.

MACCORMICK, Neil. Argumentação jurídica e teoria do direito. Tradução Waldéa Barcellos. São Paulo: Martins Fontes, 2006. p. 19-20.

NUNES JUNIOR, Amandino Teixeira. A pré-compreensão e a compreensão na experiência hermenêutica. Revista Jus Navigandi, ISSN 1518-4862, Teresina, ano 8, n. 62, 1 fev. 2003. Disponível em: <https://jus.com.br/artigos/3711>. Acesso em: 10 nov. 2018. 
OLIVEIRA, Rafael Tomáz de; Streck, Lênio Luiz. O que é isto - A hermenêutica jurídica?. Revista Consultor Jurídico. 2015. Disponível em <https://www.conjur.com.br/2015-ago-29/isto-hermeneuticajuridica>. Acesso em: 10 nov. 2018.

OLIVEIRA, Rafael Tomáz de; Streck, Lênio Luiz. É ontologicamente impossível querer mais analítica e menos hermenêutica. Revista Consultor Jurídico. 2015. Disponível em < https://www.conjur.com.br/2015-set-19/diario-classe-ontologicamente-impossivel-querer-analiticahermeneutica>. Acesso em: 10 nov. 2018.

SCHLEIERMACHER, Friedrich D. E. Hermenêutica - Arte e técnica da interpretação. Tradução e apresentação de Celso Reni Braida. Petrópolis, RJ: Vozes, 1999.

SCHMITT, Carl. O Guardião da Constituição. Tradução Geraldo de Carvalho. Belo Horizonte: Del Rey, 2007.

STRECK, Lênio Luiz. A crítica hermenêutica do Direito e a teoria da argumentação de Atienza: convergencias e divergências sobre o raciocínio jurídico. Revista Quaestio Juris, Rio de Janeiro, v. 9, n. $\quad 4$, p. 2.207-2.226, 2016. Disponível em <http://www.epublicacoes.uerj.br/index.php/quaestioiuris/article/view/25651/18889>. Acesso em 10 nov. 2018.

STRECK, Lenio Luiz. Hermenêutica Jurídica e(m) Crise: uma exploração hermenêutica da construção do Direito. 7. ed. Porto Alegre: Livraria do Advogado, 2007.

VERBICARO, Loiane Prado; OLIVEIRA, Juliana Corrêa Albuquerque de. O objetivismo moral e o interpretativo na teoria de Ronald Dworkin. Revista Eletrônica Direito e Sociedade. Canoas, Vol. 6, n. 1, 2018. Disponível em <https://revistas.unilasalle.edu.br/index.php/redes/article/view/3555/pdf>. Acesso em 22 nov. 2018.

VICTORINO, Fábio Rodrigo. Hermenêutica e pré-compreensão: o círculo hermenêutico. Conteudo Juridico, Brasilia-DF: 14 nov. 2014. Disponivel em: <http://www.conteudojuridico.com.br/?artigos\&ver=2.50619\&seo=1>. Acesso em: 18 nov. 2018.

\section{COMO CITAR ESSE DOCUMENTO:}

DA SILVA, Willy Potrich; FREIRE JÚNIOR, Américo Bedê. Analítica e hermenêutica: duas faces de uma mesma solução para a garantia da racionalidade na aplicação do direito. Revista do Direito, Santa Cruz do Sul, v. 1, n. 57, jul. 2019. ISSN 1982-9957. Disponível em: <https://online.unisc.br/seer/index.php/direito/article/view/12881>. Acesso em:

doi:https://doi.org/10.17058/rdunisc.v1i57.12881. 